\title{
A New Dynamical Index for India-Burma Trough
}

\author{
Kui Liu, ${ }^{1,2}$ Jinlin Zha, ${ }^{1}$ Ruowen Yang $\left(\mathbb{D},{ }^{1}\right.$ and Jilong Chen ${ }^{2}$ \\ ${ }^{1}$ Department of Atmospheric Science, Yunnan University, Kunming 650091, China \\ ${ }^{2}$ Center for Monsoon System Research, Chinese Academy of Sciences, Beijing 100089, China
}

Correspondence should be addressed to Ruowen Yang; yangruowen@ynu.edu.cn

Received 3 September 2017; Revised 5 February 2018; Accepted 28 February 2018; Published 3 May 2018

Academic Editor: Anthony R. Lupo

Copyright (C) 2018 Kui Liu et al. This is an open access article distributed under the Creative Commons Attribution License, which permits unrestricted use, distribution, and reproduction in any medium, provided the original work is properly cited.

\begin{abstract}
Based on the vertical velocity field of reanalysis datasets, this study defines a new dynamical index for the India-Burma trough and supports this index's advantages by analyzing reanalysis and observational datasets. For a convenient understanding, the vertical velocities of 5 levels ranging from $700 \mathrm{hPa}$ to $500 \mathrm{hPa}$ within the area of $15.625^{\circ} \mathrm{N}-24.375^{\circ} \mathrm{N}$ and $90.625^{\circ} \mathrm{E}-100.625^{\circ} \mathrm{E}$ are multiplied by -1 and summed up into a time series involving each year from 1979 to 2012 . The standardized value of the time series is defined as the index of India-Burma trough (IIBT). IIBT can reflect the characteristics of the annual strength and the interdecadal variation of the India-Burma trough. IIBT can also well reveal the relationship between the India-Burma trough and its upstream teleconnection. What is more, through a correlation analysis on the grid point precipitation field, respectively, with the IIBT and the India-Burma trough indices defined with vorticity and geopotential height, over southern Asia the correlation pattern between the IIBT and the precipitation field is found to nearly be the sum of the correlation patterns of the latter 2 indices with the precipitation. To the south of the TP, the correlation field between the IIBT and the grid point precipitation shows dipolar distribution, which is consistent with the correlation patterns of the IIBT with the vertical velocity, specific humidity, and the mid-level geopotential height in the same spatial location. IIBT is beneficial for more accurate study of the impact of the India-Burma trough on the associated weather and climate.
\end{abstract}

\section{Introduction}

The TP splits and merges the tropospheric westerlies. When westerlies meet the TP, the anticyclonically curved flow to the north side forms the dynamic high pressure ridge, whereas the other branch flow to the south cyclonically shapes the dynamic low pressure trough, which is named as the southern branch trough or the India-Burma trough [1]. Qin et al. [2] indicated that the India-Burma trough, also known as the subtropical westerly trough, is closely related to the upstream teleconnection and the Arabian Sea trough. The India-Burma trough appears in all seasons throughout a whole year, especially in the winter half year (December-May in the next year) with the highest frequencies [2]. From the perspective of climate, Suo and Ding [3] studied the structure and evolution characteristics of the subtropical south branch trough in the winter half year and pointed out that the India-Burma trough is the semipermanent trough of low pressure, appearing in the subtropical south branch westerly to the south of the plateau, in more detail which is over BOB in the winter half year. The India-Burma trough is established in October over the northern $\mathrm{BOB}$, which intensifies in winter and becomes active in spring and then transforms into the $\mathrm{BOB}$ trough in June.

The India-Burma trough is one of the most important synoptic systems affecting southern China in winter [4], whose impact on the weather and the short-term climate may even extend to the eastern China and Japan [5]. Qin et al. [2] revealed that the onset of the rainy season in southwestern China is caused by the interaction between the India-Burma trough and the cold air from high latitudes. He et al. [6] believed that the burst of the South China Sea monsoon is associated with the India-Burma trough. It supplies most of the moisture from $\mathrm{BOB}$ when the moisture from the western North Pacific (WNP) is interrupted to a large extent $[7,8]$. Previous studies also expounded the relationship between the India-Burma trough and El Niño, through which Li et al. [9] exhibited the reason for the drought in northern and northwestern China. Zhao et al. [10] deemed that the number of days of spring sand-dust storm in northwestern China is 
also linked to the India-Burma trough. Suo and Ding [3] pointed out that the India-Burma trough is connected to the onset of the summer monsoon in China. Since the IndiaBurma trough has an important influence on the weather and climate, it is one of the important factors for the weather forecast in China.

In order to study the India-Burma trough and its effects on the weather and climate, many scholars have defined the India-Burma trough index from different perspectives.

Zhang et al. [11] defined the India-Burma index with the averaged geopotential height in the area of $15^{\circ} \mathrm{N}-27.5^{\circ} \mathrm{N}$ and $80^{\circ} \mathrm{E}-100^{\circ} \mathrm{E}$ at $500 \mathrm{hPa}$ and pointed out that the IndiaBurma trough was relatively strong in the winter half year from the 1950s to the 1970s. Especially in the 1960s, the trough was the strong, and after that it began to weaken. The strength of the India-Burma trough is not all the same in different periods, with quasi 17-year oscillation in the low frequency band, and quasi 3-year and quasi 8-year cycle in the medium-high frequency band [11]. Wang et al. [12] defined the India-Burma index with the averaged vorticity in the area of $15^{\circ} \mathrm{N}-25^{\circ} \mathrm{N}$ and $80^{\circ} \mathrm{E}-100^{\circ} \mathrm{E}$ at $700 \mathrm{hPa}$ and pointed out that the index defined with vorticity is better than that defined by geopotential height. They pointed out the increasing tendency of the India-Burma trough strength after 1978 and further studied the differences of the IndiaBurma trough's impacts on the climate of South and East Asia between 1949-1977 and 1978-2010. Lu and Ren [13] agreed with the conclusion of Wang et al. [12] and further explore the fact that SST forcing is an important factor for IIBT interdecadal deepening. The India-Burma trough indices defined from different perspectives could not give an unified answer whether the trough grows stronger or weaker after 1978. Compared to other weather and climate systems of southwestern China and South Asia, the IndiaBurma trough is relatively active in winter and spring, and it becomes more and more important for the annual prediction of the temperature and precipitation (including drought) there. The drought occurring in the low-latitude highlands in southwestern China is frequent and widespread [14]. From the winter of 2009 to the spring in 2010, the most serious drought since 1951 occurred there [15-21]. Many researches had shown that the weak India-Burma trough resulted in less water vapor transportation from the BOB to the highlands [22-25], which is one important reason of this drought event. The variety of definitions for the IndiaBurma trough index illustrates that no particular physical parameter fully describes it. Therefore, the researchers could not well study its real weather and climate significance in South Asia and southwestern China, which this manuscript investigates. The data and methods used for the study are presented in Section 2. Section 3 describes the results and analysis. Conclusion and discussion are given in Section 4.

\section{Data and Methods}

For our analyses, the monthly Modern-Era Retrospective Analysis for Research and Applications (MERRA) atmospheric circulation data provided by Goddard Earth Sciences Data and Information Sciences Center (GES DISC) and
Global Modeling and Assimilation Office (GMAO) is used. MERRA is a reanalysis for the satellite era using a major new version of the Goddard Earth Observing System Data Assimilation System Version 5 (GEOS-5), which helps to study the meteorological phenomena of weather and climate time scales. The data spans from 1979 to present, with spatial resolution $1.25^{\circ} \times 1.25^{\circ}$, and the meteorological elements used are geopotential height, vertical velocity, horizontal wind field, and specific humidity. The precipitation data used is the Global Precipitation Climate Center (GPCC) monthly precipitation data (V6 and V4), with spatial resolution $1^{\circ} \times 1^{\circ}$ spanning from 1979 to 2012 . The monthly precipitation data of 148 stations in low-latitude highlands from 1979 to 2012 is also used, which is provided by the Climate Center of Yunnan Meteorological Administration. All the datasets are only used during winter half year (winter and spring). The correlation analysis, normalization of time series, Mann-Kendall (M-K), and Empirical Orthogonal Function (EOF) approaches are employed. We introduce the special calculation of normalization and $\mathrm{M}-\mathrm{K}$ methods in the following [26].

If $x$ series has $n$ samples, we can get the normalization $y$ by three steps:

$$
\begin{aligned}
& \bar{x}=\frac{1}{n} \sum_{i=1}^{n} x_{i}, \\
& S=\sqrt{\frac{1}{n} \sum_{i=1}^{n}\left(x_{i}-\bar{x}\right)^{2}}, \\
& y_{i}=\frac{x_{i}-\bar{x}}{S} .
\end{aligned}
$$

For M-K method, suppose that the $x$ series has $n$ samples, and then construct a rank.

$$
\begin{aligned}
& s_{k}=\sum_{i=1}^{k} r_{i}, \quad k=2,3, \ldots, n, \\
& r_{i}=\left\{\begin{array}{ll}
+1, & \text { if }\left(x_{i}>x_{j}\right) \\
0, & \text { if }\left(x_{i} \leq x_{j}\right)
\end{array}, \quad j=1,2, \ldots, i,\right. \\
& \mathrm{UF}_{k}=\frac{\left[s_{k}-E\left(s_{k}\right)\right]}{\sqrt{\operatorname{var}\left(s_{k}\right)}}, \quad k=1,2, \ldots, n .
\end{aligned}
$$

In formula (4) $\mathrm{UF}_{1}=0 . E\left(s_{k}\right)$ and $\operatorname{var}\left(s_{k}\right)$ are the average value and variance of $s_{k}$ :

$$
\begin{aligned}
E\left(s_{k}\right) & =\frac{k(k-1)}{4}, \\
\operatorname{var}\left(s_{k}\right) & =\frac{k(k-1)(2 k+5)}{72},
\end{aligned}
$$

$$
k=2,3, \ldots, n \text {. }
$$

Then reverse $x$, repeat above steps, and make sure that

$$
\begin{aligned}
& \mathrm{UB}_{k}=-\mathrm{UF}_{k} \quad(k=n, n-1, \ldots, 1), \\
& \mathrm{UB}_{1}=0 .
\end{aligned}
$$




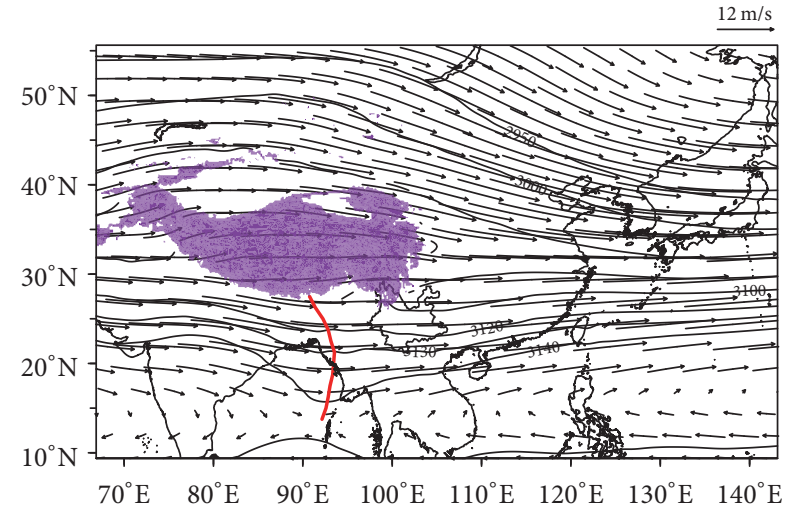

(a)

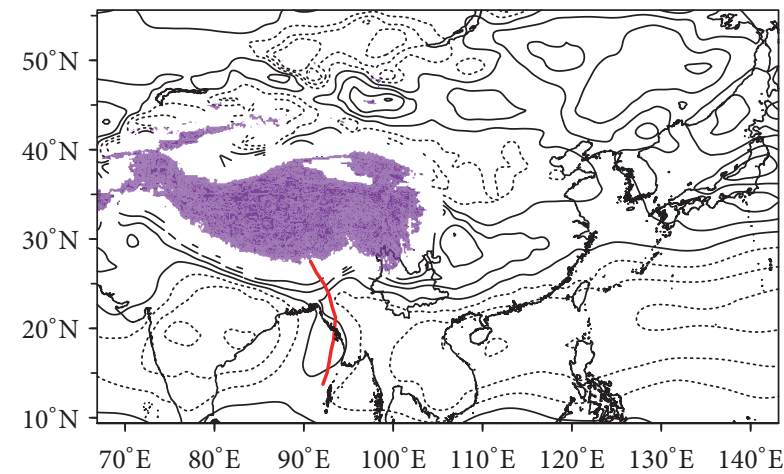

(c)

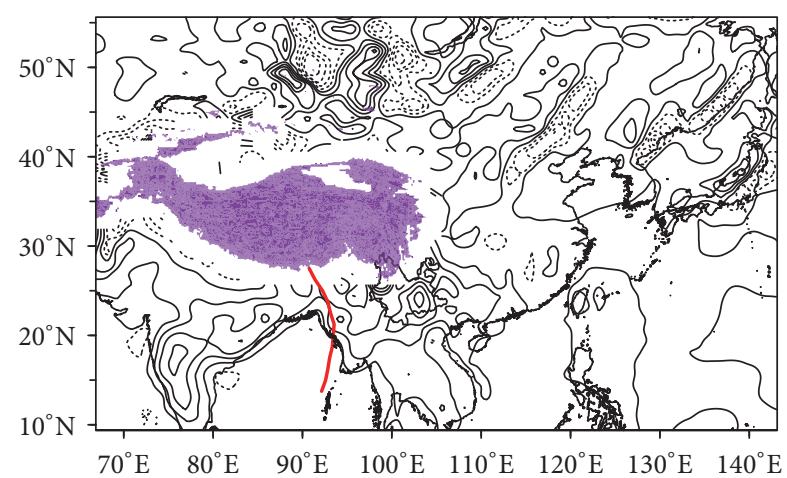

(b)

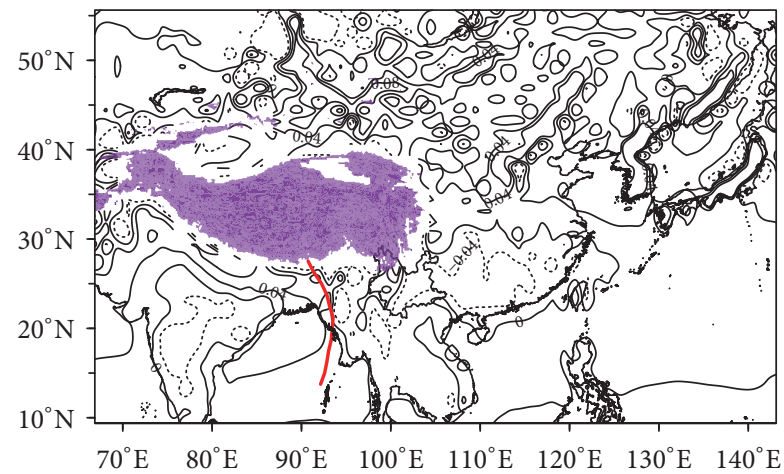

(d)

Figure 1: (a) The geopotential height (unit: gpm) and wind (unit: $\mathrm{m} \mathrm{s}^{-1}$ ), (b) the divergence field (contour interval: $2 e-6 \mathrm{~s}^{-1}$ ), (c) vorticity (interval: $5 e-6 \mathrm{~s}^{-1}$ ), and (d) vertical velocity (interval: $0.05 \mathrm{~Pa} \mathrm{~s}^{-1}$ ) over $700 \mathrm{hPa}$ in winter half year (from December to the next May) from 1978/1979 to 2011/2012 (written as 1979-2012). The violet area is the TP, and red line denotes trough axis (same for the following context).

The critical value of $95 \%$ significance is 1.96 and the UF > 0 (UF $<0$ ) indicates the upward (downward) trend of the serial, with exceeding the critical value denoting the significant upward (downward) trend. The intersection point between the critical lines represents the point of mutation.

\section{Results Analysis}

3.1. The Analysis of the Meteorological Elements in the IndiaBurma Trough Region. TP is the most important topographic feature of the Asian continent. As shown in Figure 1(a), the westerlies form a northern branch to the north of TP and a southern branch in the other side, with a ridge and a trough (India-Burma trough), respectively. The India-Burma trough stretches southward from the southern hill of TP to the north of the $\mathrm{BOB}$ (near $15^{\circ} \mathrm{N}$ ). The trough region is located in the northern part (near $20^{\circ} \mathrm{N}$ ) of the $\mathrm{BOB}$, and there is a high pressure ridge due to the terrain blocking effects on the air current over the India peninsula. When the air flow in front of the India-Burma trough enters Yunnan province, a weak ridge is formed by the terrain effects. As portrayed in Figure 1(b), at $700 \mathrm{hPa}$ the divergence in front and back of the trough above the land is positive, which means divergence. Maybe because of the blocking effect of the Deccan Plateau in India on the air flow, a stationary anticyclone is located in the back of the trough (seen from Figure 1(a)), which leads to the appearance of divergence in the back of trough, although there exists convergence in the back of trough in general, whereas the divergence over $\mathrm{BOB}$ is negative, displaying a convergent state. In Figure 1(c), the climatological mean of the vorticity on $700 \mathrm{hPa}$ is negative to the west of the trough axis, positive at the trough axis, and negative east of the trough axis in the southern part of Yunnan. Regarding $700 \mathrm{hPa}$ vertical motion (Figure $1(\mathrm{~d})$ ), upward vertical motion is evident east of the tough axis and sinking motion west of the trough axis. It can be seen from the distribution of the trough lines in Figure 1 that the India-Burma trough can be discerned in various meteorological element fields at $700 \mathrm{hPa}$, with obvious ascending motion in front of the trough and a clear separation of the negative (ascending) area in front of the trough and the positive (sinking) area in the trough region, in view of which the definition of the India-Burma index based on the vertical velocity in front of the trough can be a good one.

3.2. Defining the India-Burma Trough Index with Vertical Velocity. Wang et al. [12] defined the India-Burma trough index with the $700 \mathrm{hPa}$ vorticity to study the India-Burma trough's influence on climate anomalies in East and South Asia. However, Wang et al. [12] also suggested that the IndiaBurma trough index could also be defined by vertical velocity downstream of the trough axis. 


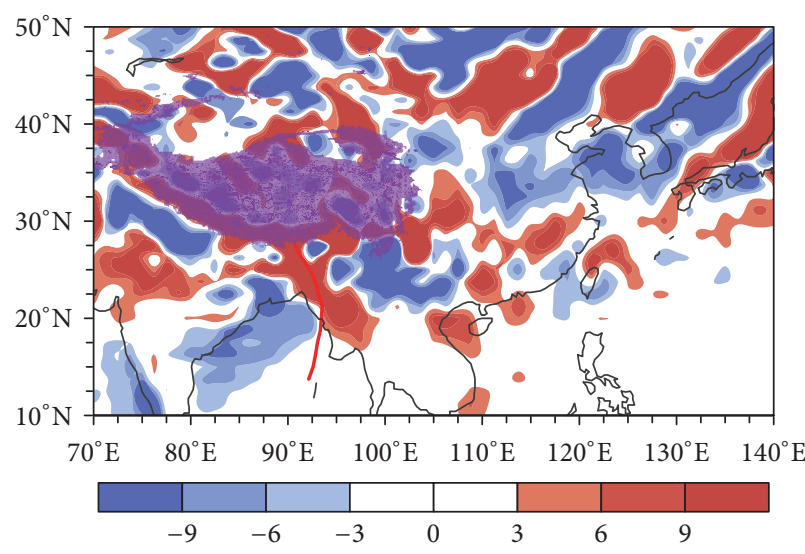

(a) $700 \mathrm{hPa}$ relative vorticity advection

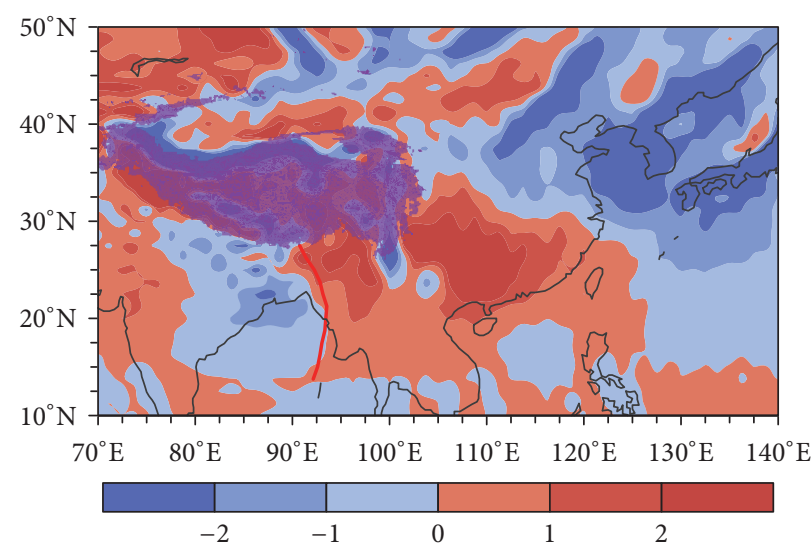

(b) $700 \mathrm{hPa} \mathrm{T}$ advection

FIGURE 2: Same as Figure 1, but for $700 \mathrm{hPa}$ (a) relative vorticity advection (unit: $1 e-11 \mathrm{~s}^{-2}$ ) and (b) temperature advection (unit: $1 e-5 \mathrm{~K} \mathrm{~s}{ }^{-1}$ ).

As depicted in Figure 2(a), there exists strong negative relative vorticity in the back of the trough and positive vorticity advection in front of the trough at $700 \mathrm{hPa}$, the latter of which is in favor of the occurrence of ascending motion. And, in front of the trough (Figure 2(b)), there is positive temperature advection, which also supports the occurrence of rising motion. For example, Li et al. [9] pointed out that the ground thermal effects of the TP can affect the strength of the India-Burma trough. The vertical motion not only reflects the relative vorticity, but also includes the influence of the temperature advection; therefore the vertical motion is used to measure the India-Burma trough.

\subsection{The India-Burma Trough Index and Its Connection with} Various Meteorological Elements. As shown in Figure 1(d), the region in front of the India-Burma trough covers $15.625^{\circ} \mathrm{N}-24.375^{\circ} \mathrm{N}$ and $90.625^{\circ} \mathrm{E}-100.625^{\circ} \mathrm{E}$. For the rest of the manuscript, vertical velocity is multiplied by -1 . As the India-Burma trough appears mainly in the mid-low layers of the troposphere [12], the vertical velocity in front of the trough region on a total of 5 layers from $700 \mathrm{hPa}$ to $500 \mathrm{hPa}$ is summed up in each year from 1979 to 2012 into a sequence, whose standardized series are used to define the index of India-Burma trough (IIBT).

$$
\mathrm{IIBT}=-\mathrm{Norm}\left[\prod_{700 \mathrm{hPa}}^{500 \mathrm{hPa}} \operatorname{sum}\left(\omega\left(15.625^{\circ}-24.375^{\circ} \mathrm{N}, 90.625^{\circ}-100.625^{\circ} \mathrm{E}\right)\right)\right]
$$

where sum indicates sum-up, $\prod_{700 \mathrm{hPa}}^{50 \mathrm{hPa}}$ represents sum-up from $700 \mathrm{hPa}$ to $500 \mathrm{hPa}$, and Norm means normalization.

Wang et al. [23] argued that the weak India-Burma trough is one of the reasons for the most severe drought event since 1951 in southwestern China from the winter of 2009 to spring of $2010[22,27]$. Figure 3(a) illustrates that IIBT is strongly negative for the extreme drought year of 2010 . However, this drought persists to year 2012 (e.g., [28]), even though IIBT is no longer strongly negative. However, other droughts correspond well to negative IIBT values exceeding one standard deviation (e.g., 1982, 2005, 2009, and 2010 in Figure 3(a)). These illustrate that IIBT can well depict the characteristics of the India-Burma trough strength in the years with extreme climate events generally. Figure 3(b) shows multiple intersections between the UF and the UB curves before 1984, which indicates that annual variation exists for the India-Burma trough before 1984. After the year 1984, the India-Burma trough strength has an increasing tendency, and the trend becomes significant around 2000, exceeding 95\% confidence level. Figure 4 demonstrates the
EOF analyses of the precipitation of 148 stations in lowlatitude highlands, located in front of the India-Burma trough. The correlation coefficient between IIBT and the $\mathrm{PCl}$ of the 1st EOF mode of the precipitation of these 148 stations is 0.55 , and the value in nearly all the spatial field of the 1st EOF mode is consistently positive or negative (Figure 4(a)). So, IIBT not only reflects annual variation characteristics of the India-Burma trough, but also reveals its interdecadal variation characteristics. IIBT also embodies the close relationship between India-Burma trough and relatedarea precipitation.

As shown in Figure 5(a), there is, respectively, one trough in the Arabian Sea and in the northern $\mathrm{BOB}$ on $700 \mathrm{hPa}$, which are called the Arabian Sea trough and the IndiaBurma trough. In the back of each trough, there exists one anticyclone, each being a part of the South Asia high. The Arabian Sea trough vorticity and IIBT are negatively related, while the anticyclone vorticity in the east of South Asia high is positively related to IIBT. As the Arabian Sea trough becomes weak, the downstream anticyclone in the east of the South Asia high is weak, and the IIBT increases, indicating 


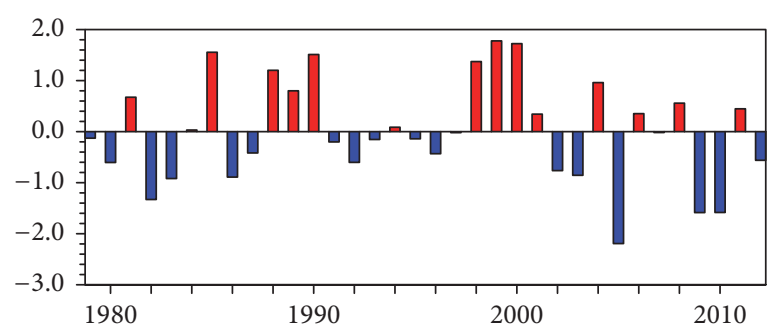

(a)

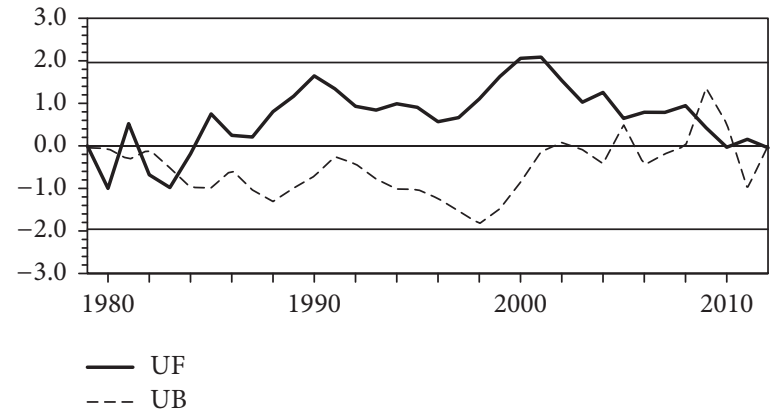

(b)

Figure 3: (a) Time series of IIBT and (b) M-K analysis of IIBT; straight line indicates the critical value of $95 \%$ significance $t$-test.

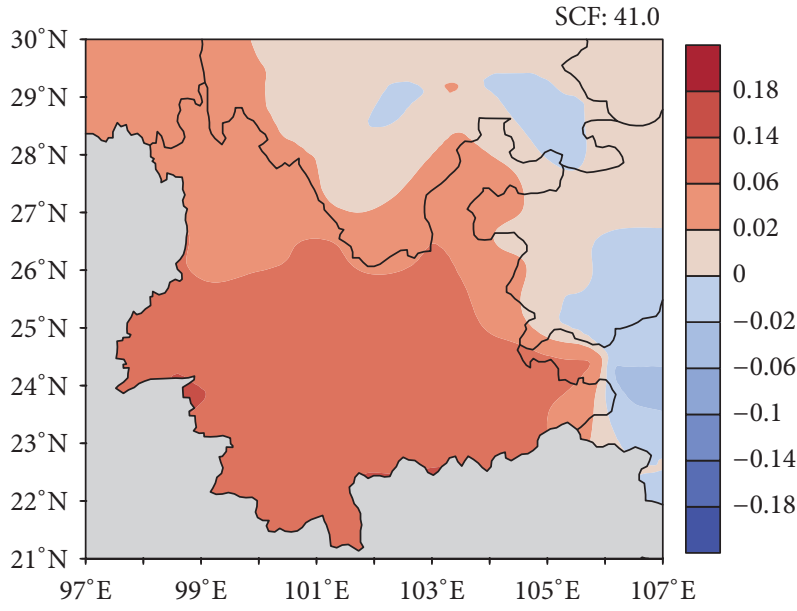

(a) EOF 1

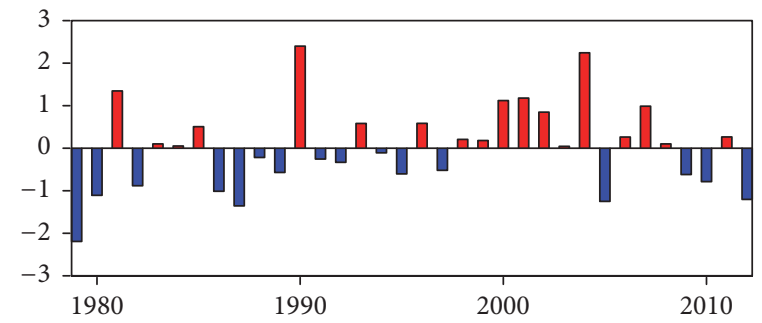

(b) PCl (1979-2012)

FIGURE 4: (a) The first EOF mode of observational precipitation of 148 stations in winter half year over low-latitude highlands and (b) its corresponding standardized temporal serial PC1.

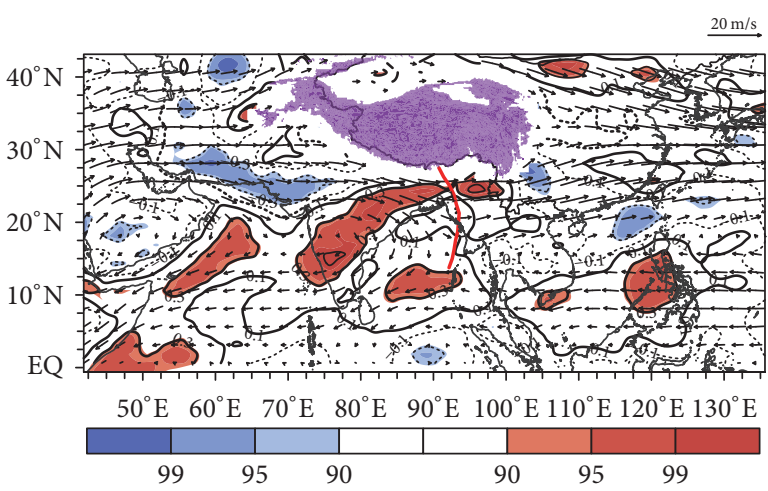

$(\%)$

(a)

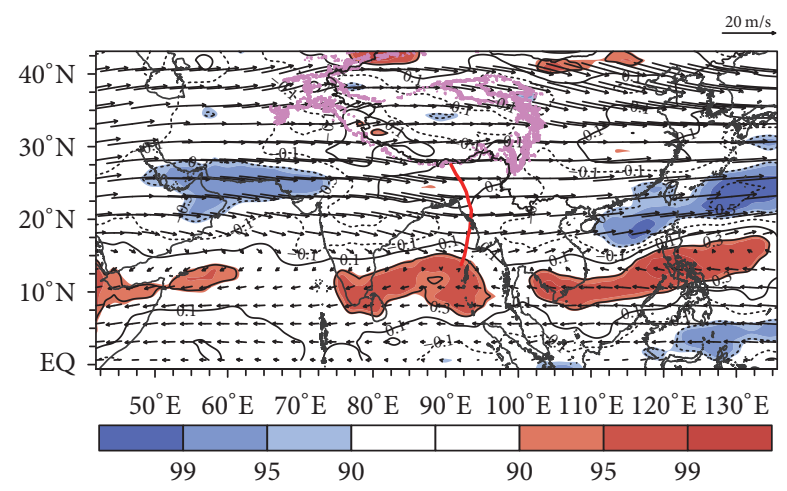

(\%)

(b)

FIGURE 5: The correlation between vorticity and IIBT (contour) and the mean wind field of the winter half year (unit: $\mathrm{m} \mathrm{s}^{-1}$ ). (a) For $700 \mathrm{hPa}$ and (b) for $500 \mathrm{hPa}$. The different shadings from light to dark have passed the significance test with more than $90 \%$, $95 \%$, and $99 \%$ confidence level, respectively; the red (blue) areas denote positive (negative) correlation areas, and the area encircled by yellow line is the TP (the same for the following context). 


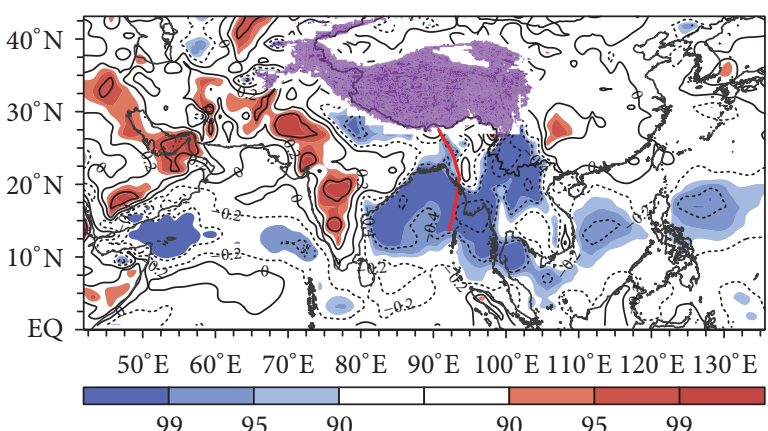

(\%)

(a)

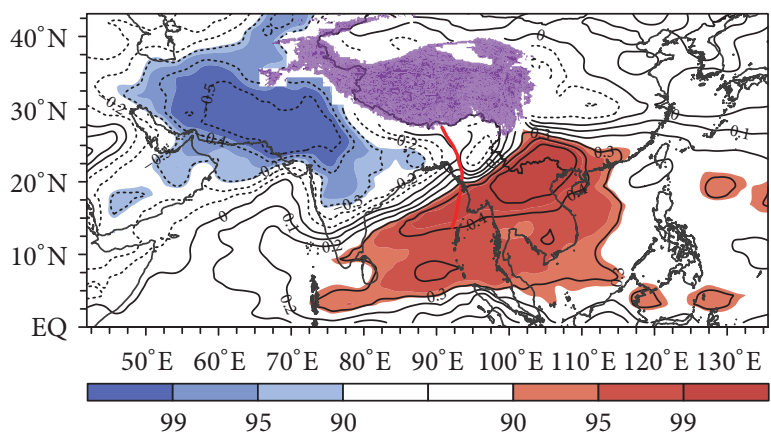

(\%)

(c)

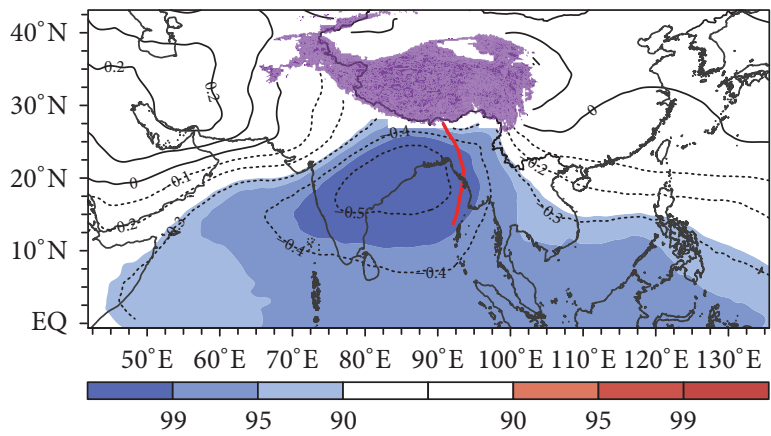

(\%)

(e)

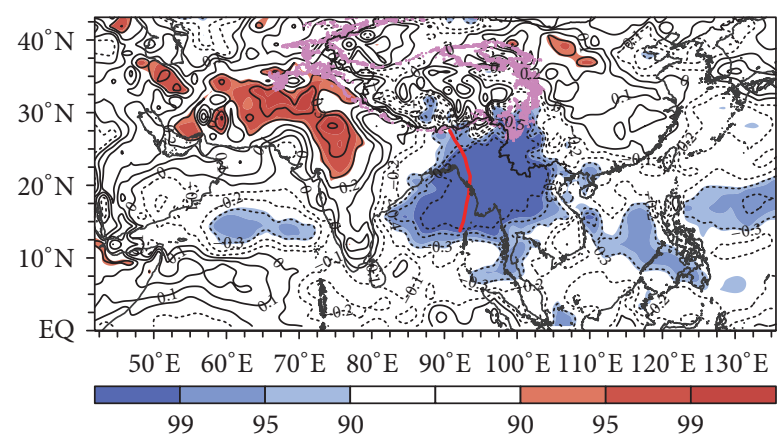

$(\%)$

(b)

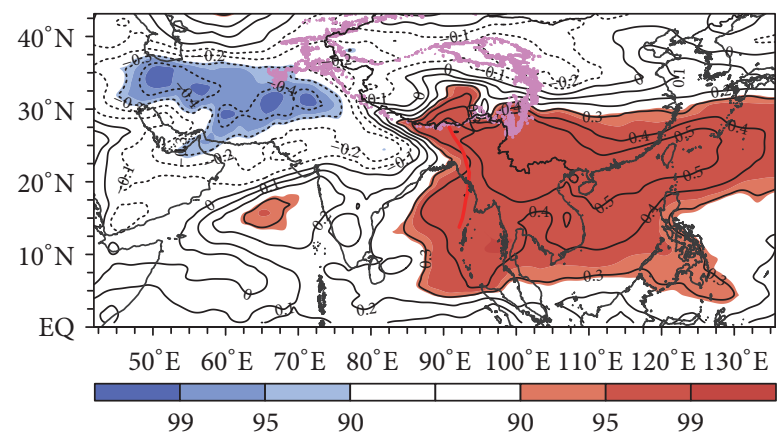

(\%)

(d)

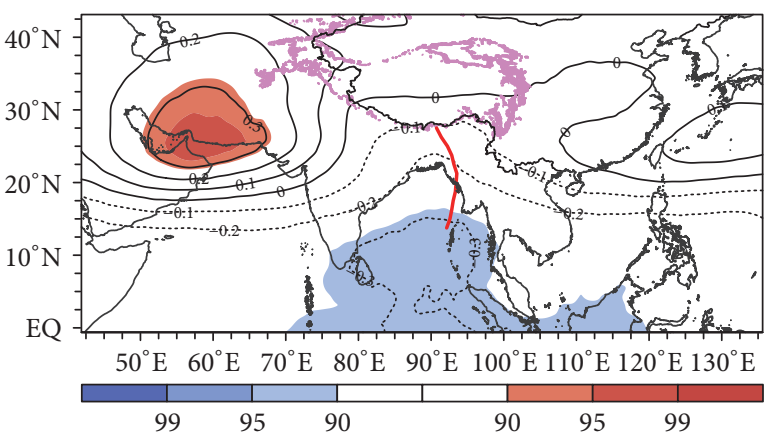

(\%)

(f)

Figure 6: The correlation between the vertical velocity (a, b), specific humidity (c, d), geopotential height (e, f), and IIBT ((a), (c), and (e) for $700 \mathrm{hPa}$; (b), (d), and (f) for $500 \mathrm{hPa}$ ) in winter half year. Additionally, the different shadings from light to dark have passed the significance test with more than $90 \%, 95 \%$, and $99 \%$ confidence level, respectively; the red (blue) areas denote the positive (negative) correlation areas, respectively.

that the trough becomes stronger, and vice versa. From the $500 \mathrm{hPa}$ analysis (Figure 5(b)), it can also be seen that when the upstream anticyclone in the west of the South Asia high becomes strong (or the Arabian Sea trough becomes weak), the zonal air flow along the periphery of the high is more likely to turn into northerlies, and meanwhile the anticyclone in the east becomes weak and the India-Burma trough grows strong when the peripheral air flow of the subtropical high near $100^{\circ} \mathrm{E}-130^{\circ} \mathrm{E}$ along $10^{\circ} \mathrm{N}$ becomes weak. According to the method provided by Yang and Sun [29] and considering the average position of the subtropical high in the research time span, the meridional position index of the subtropical high is calculated with the averaged relative vorticity over $500 \mathrm{hPa}$ within $14^{\circ} \mathrm{N}-24^{\circ} \mathrm{N}$ and $110^{\circ} \mathrm{E}-135^{\circ} \mathrm{E}$, whose correlation coefficient with IIBT is 0.28 , indicating passing $90 \%$ significance test. This illustrates that when the India-Burma trough grows strong, the subtropical high moves eastward, which causes weak air flow along the subtropical high periphery near the India-Burma trough. IIBT reflects the relationship between the India-Burma trough activity and the upstream fluctuation of the south branch westerly and its connection with the South Asia high and the subtropical high.

As shown in Figure 6(a), it can be seen that when the India-Burma trough grows strong, at $700 \mathrm{hPa}$, the vertical 


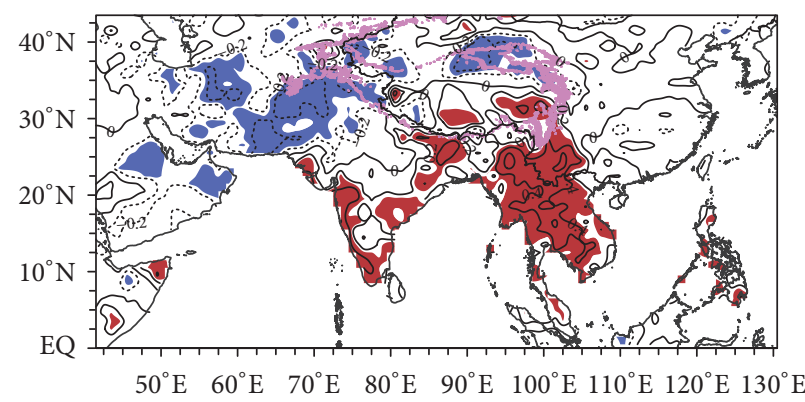

(a)

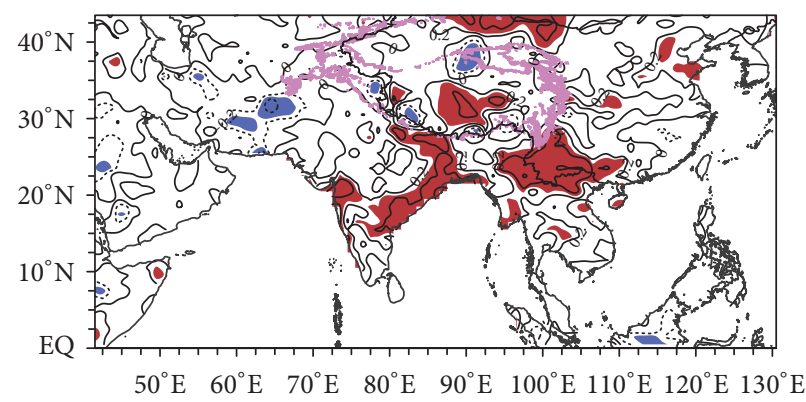

(b)

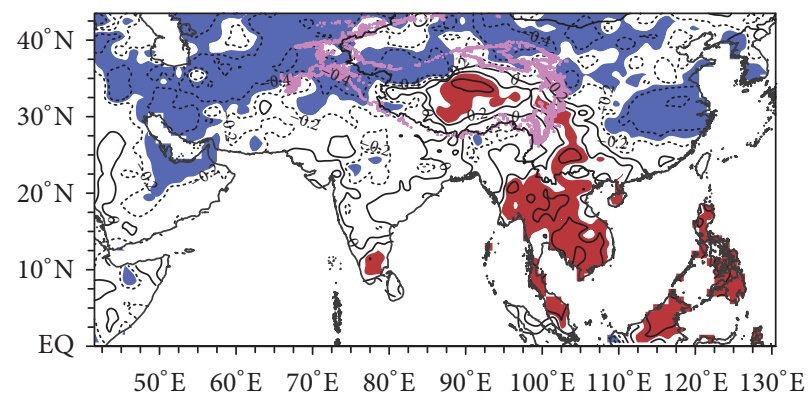

(c)

FIGURE 7: The correlation between IIBT (a), the India-Burma trough index defined with vorticity (b), the India-Burma trough index defined with geopotential height (c), and the grid point GPCP precipitation in winter half year, respectively. The shaded areas pass significance test more than $90 \%$ confidence level, where the red (blue) areas denote the areas of more (less) rainfall when the India-Burma trough is strong.

ascending motion is enhanced in the zonal circulation between $10^{\circ} \mathrm{N}$ and $20^{\circ} \mathrm{N}$. The descending motion in the back of the Arabian Sea trough is enhanced, and the vertical motion in front of the India-Burma trough obviously becomes strong. The $500 \mathrm{hPa}$ contour (Figure 6(b)) also shows the above features, but with less negative correlation area and more positive correlation area whose center moves to the Iran plateau. Li et al. [9] pointed out that as the IndiaBurma trough strengthens, the convective activity near the $\mathrm{BOB}$ becomes more vigorous, which is reflected by IIBT. In addition, from both $700 \mathrm{hPa}$ and $500 \mathrm{hPa}$ in Figures 6(c) and $6(\mathrm{~d})$, it can be seen that as the India-Burma trough index increases the specific humidity values in front of the trough increase, with more water vapor from the tropical ocean, whereas the air flow turns drier in the Iran plateau in the India-Burma trough upstream. When the India-Burma trough grows strong, the vertical motion becomes vigorous, with the water vapor transporting upwards from the low layer, and therefore the positive correlation between the moisture in front of the trough on $500 \mathrm{hPa}$ and IIBT is more significant, compared to that in $700 \mathrm{hPa}$. The India-Burma trough is closely related to the water vapor advection in front of the trough, which is also reflected by IIBT.

Additionally, Figures 6(e) and 6(f) show that when the IIBT is more intense, the geopotential height in the IndiaBurma trough region decreases, whereas the air flow in the back of the Arabian Sea trough accumulates, with greater geopotential height values, which is consistent with the analysis of Figures 5, 6(a), and 6(b). The variations of the vertical velocity, specific humidity, and the geopotential height are important indices, which reflects the variations of the IndiaBurma trough, especially the variations of specific humidity, which is the reflection of the air flow strength in front of the trough and an important factor affecting the precipitation of the low-latitude highlands. The significant correlations between IIBT and these meteorological elements, as well as the consistency in the correlation patterns, illustrate that IIBT can reflect the India-Burma trough structure.

\subsection{The Comparison between IIBT and Other India-Burma} Trough Indices. Wang et al. [12] used averaged vorticity of the area of $15^{\circ} \mathrm{N}-25^{\circ} \mathrm{N}$ and $80^{\circ} \mathrm{E}-100^{\circ} \mathrm{E}$ at $700 \mathrm{hPa}$ to define the India-Burma trough index, whose correlation coefficient with IIBT is 0.46 . Suo and Ding [3] used $700 \mathrm{hPa}$ anomaly series of the mean geopotential height of the area of $15^{\circ} \mathrm{N}-25^{\circ} \mathrm{N}$ and $80^{\circ} \mathrm{E}-100^{\circ} \mathrm{E}$ to define the India-Burma trough index, whose correlation coefficient with IIBT is -0.48 . These 2 correlation coefficients have passed the $99 \%$ significance test with critical value of 0.44 . The correlation patterns of these 3 indices with GPCC grid point precipitation are displayed in Figure 7. From the correlation pattern between IIBT and GPCC precipitation (Figure 7(a)), it is evident that when the India-Burma trough becomes strong in winter and spring, the precipitation of the southeast corner of TP, southwestern China to the eastern India-Burma trough, and the IndoChina Peninsula increases, as well as the rainfall of the areas along the coastline in the Indian subcontinent, mainly restricted to $10^{\circ} \mathrm{N}-30^{\circ} \mathrm{N}$ and $80^{\circ} \mathrm{E}-105^{\circ} \mathrm{E}$. But the precipitation in the Iran plateau area decreases, mainly confined to $25^{\circ} \mathrm{N}-35^{\circ} \mathrm{N}$ and $55^{\circ} \mathrm{E}-80^{\circ} \mathrm{E}$. So, the correlation field between 


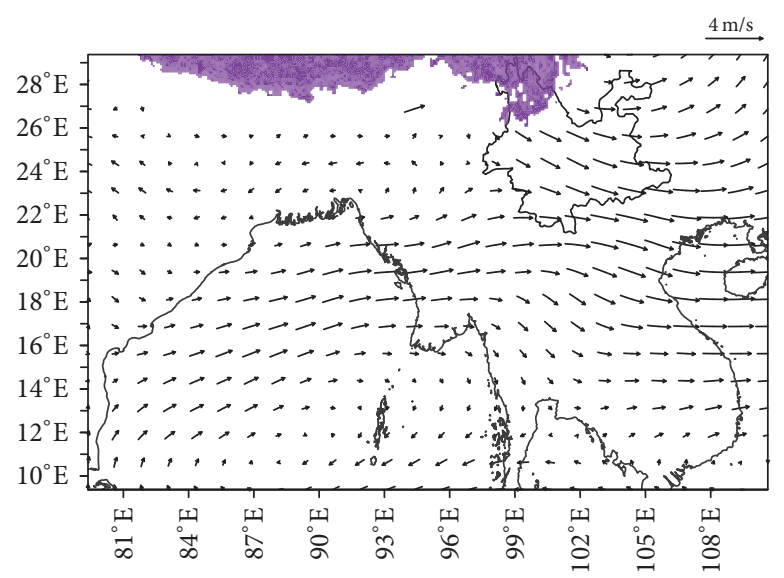

(a)

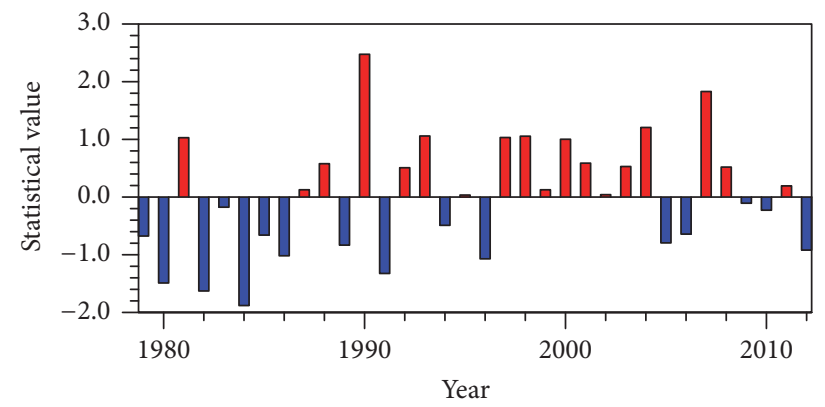

(b)

Figure 8: (a) In winter half year the wind field of 2010 minus the average wind field from 1979 to 2012 at $700 \mathrm{hPa}$ (unit: $\mathrm{m} \mathrm{s}^{-1}$ ). (b) the India-Burma trough index defined with vorticity.

IIBT and the precipitation takes on a dipolar pattern to the south of the TP. This dipole type appears in the same spatial position in Figures 6(a), 6(b), 6(c), 6(d), and 6(f), in a good agreement with each other, which indicates that IIBT well reflects the influence of the India-Burma trough strength on the meteorological elements in the low-latitude highlands in China, the southeast corner of the TP, the Indo-China peninsula, and the Indian subcontinent, as well as the impact degree of the precipitation there. Compared with Figure 7(a), the India-Burma trough index defined with vorticity reflects significantly less influence scope from the trough on the precipitation of the Indo-China peninsula and the Indian peninsula, as well as fewer areas of less precipitation in the Iran plateau. The dipole type (Figure 7(b)) similar to Figure 7(a) still exists, but very weak, which means that the index cannot reflect well the wide influence degree of the India-Burma trough on the precipitation in South Asia. The correlation between the India-Burma trough index defined with geopotential height and the grid point precipitation is shown in Figure 7(c), which can reflect the impact of the trough on the precipitation in Indo-China peninsula, but not for the rainfall in southwestern China. The water vapor transportation of the India-Burma trough is beneficial to the precipitation in South China and even serves as an important moisture source in the prerainy period. However, Figure 7(c) shows that the stronger India-Burma trough is unfavorable to the precipitation in South China. As shown in Figure 5, the Philippines and Malaysia are under the control of the subtropical high in winter and spring; possibly the subtropical high is an important factor for the amount of the rainfall there. Under the consideration of all these conditions, the India-Burma trough index defined with geopotential height seems unable to reflect the real impact degree of the trough on the surrounding areas.

Except for the Philippines and Malaysia, the areas passing the significance test in South Asia in Figure 7(a) are nearly the combination of Figures 7(b) and 7(c), IIBT can better reflect the important influence of the India-Burma trough on the precipitation in South Asia, and the consistence of the dipole in Figures 6(a), 6(b), 6(c), 6(d), and 6(f) with Figure 7(a) reveals that IIBT can better describe the coordination between the trough and the surrounding circulation background.

\section{Conclusion and Discussion}

The upward motion is closely associated with temperature advection and vorticity advection, which often vary with the change of the weather or climate. So, it can affect directly the related-area precipitation during the winter half year, which is an important source to local water supply for domestic water in autumn and early spring crop growth. To facilitate the understanding, the vertical velocity is multiplied by -1 , and the vertical velocities in front of the trough on a total of 5 layers from $700 \mathrm{hPa}$ to $500 \mathrm{hPa}$ are summed up year by year spanning 1979 to 2012, which after standardization is defined as the index of India-Burma trough (IIBT).

IIBT can reflect the strength of India-Burma trough in the years with extreme climate events. As shown in Figure 8(a), in the winter and spring of 2009-2010, compared with the average state of 1979-2012, an anomalous anticyclone is excited in the India-Burma trough region, and the trough is evidently weak, which is in accordance with the situation in IIBT series (Figure 3(a)). In addition, IIBT negative anomaly years $(1982,2005,2009$, and 2010) also conform to this rule. Since the 1970s, dramatic changes occurred in many parts of the world [30,31], with more extreme weather and climate events. The index defined by vorticity cannot reflect these events well (Figure 8(b)). Under such background, employing IIBT to describe the India-Burma trough can well characterize its annual variation.

IIBT reflects the relationship between the trough and the upstream fluctuation of the southern branch westerlies. When the anticyclone in the west of the South Asia high is enhanced, the zonal air flow along the periphery of the high is more likely to become northerlies; at the same time 
the anticyclone in the east of South Asia high becomes weak, and the IIBT is more intense and the trough turns out to be stronger. And the relationship between the IndiaBurma trough and the upstream fluctuation is also reflected in the precipitation. When the trough grows strong, the precipitation of the Iran plateau decreases. IIBT also reveals the correlation between the trough and the surrounding weather and climate system, as well as the trough structure. When the trough grows strong, the peripheral air flows of the South Asia high and subtropical high become weak, and the sinking motion in the back of the Arabian trough is enhanced. The vertical motion in front of the India-Burma trough significantly becomes strong, and the specific humidity in front of the trough increases; meanwhile the geopotential height in the trough region decreases.

Through the correlation of IIBT and other India-Burma trough indices separately defined with vorticity and geopotential height, with the grid point precipitation, it is found that the correlation pattern of IIBT with precipitation is nearly the sum as the latter two with precipitation over South Asia. The correlation field takes on a dipole type to the south of the TP, which appears in the same spatial position of the correlation fields of IIBT with vertical velocity, specific humidity, and the mid-level geopotential height, very consistent with each other. The India-Burma trough is a major moisture source for the southwestern China in winter and spring. As shown in Figure 7, the India-Burma trough has important effects on the precipitation in southwestern China, which is also verified by the observational data from 148 stations in the low-latitude highlands (including Yunnan, the south of Sichuan, the west of Guangxi, and the west of Guizhou) in southwestern China. Spring is the most active stage of the India-Burma trough [3], and during this period the correlation field of the observational data of the meteorological station with IIBT has 106 ( $71.6 \%$ of the total) stations passing the $95 \%$ significance test, which reveals the influence of magnitude and degree of the trough on the spring precipitation; the correlation linked index defined with vorticity and precipitation also reflects the influence on rainfall from the trough, with 95 stations passing the 95\% significance test, whereas the index defined with geopotential height fails to reach the accuracy, only with 62 stations passing the $95 \%$ significance test (figure omitted).

The correlation coefficient between IIBT and the PCl of the 1st EOF mode of the precipitation of these 148 stations is 0.55 (Figure 4 ). Through IIBT, the study on the specific impact of the India-Burma trough on the precipitation in South Asia is worth delving more deeply.

\section{Conflicts of Interest}

The authors declare that there are no conflicts of interest regarding the publication of this paper.

\section{Acknowledgments}

The monthly Modern-Era Retrospective Analysis for Research and Applications atmospheric circulation data is provided by Goddard Earth Sciences Data and Information
Sciences Center (GESDISC). The precipitation data used here is the Global Precipitation Climate Center (GPCC) monthly precipitation data (V6 and V4). The monthly precipitation data of 148 stations in low-latitude highlands is provided by the Climate Center of Yunnan Meteorological Administration. The authors acknowledge all the data sources. This study is sponsored by the National Key Research and Development Program of China Grant no. 2017YFC1404002, the National Natural Science Foundation of China (U1502233, Grant no. 41375082), and Yunnan Province Education Department Project (2017YJS106).

\section{References}

[1] J. C. Yang, S. Y. Tao, and T. C. Yeh, Meteorology of the Tibetan Plateau, China Science Press, 1960, pp. 280.

[2] J. Qin, J. H. Ju, and M. E. Xie, "Weather and Climate in Low Latitudes Plateau," China Meteorological Press, p. 210, 1997 (Chinese).

[3] M. Q. Suo and Y. H. Ding, "Structures and evolutions of the wintertime southern branch trough in the subtropical westerlies," Journal of the Atmospheric Sciences, vol. 33, pp. 425442, 2009 (Chinese).

[4] S. Y. Tao, "Influence of the India-Burma trough on the weather of southern China in winter," Acta Meteorological Sinica, vol. 23, pp. 172-192, 1952 (Chinese).

[5] T. M. Wang, G. X. Wu, and R. J. Wan, "Influences of the thermal and dynamical forcing of the Tibetan Plateau on the circulation over the Asian monsoon region," Plateau Meteorol, vol. 27, pp. 1-9, 2008 (Chinese).

[6] J. H. He, C. H. Sun, Y. Y. Liu, J. Matsumoto, and W. Li, "Seasonal transition features of large-scale moisture transport in the Asian-Australian monsoon region," Advances in Atmospheric Sciences, vol. 24, no. 1, pp. 1-14, 2007.

[7] X. Duan, Y. Tao, Xu. ML et al., "Influence of south branch trough of westerlies on weather of Yunnan province," Plateau Meteor, vol. 31, no. 4, pp. 1059-1065, 2012 (Chinese).

[8] T. F. Zhang, Y. B. Lu, J. Zhang et al., "Contrast analysis of 4 heavy snow events in Yunnan since," Journal of Meteorological Science, vol. 18, pp. 64-72, 2000.

[9] D. L. Li, V. He, X. Tang, and Y. Hou, "Relationship between the intensity of surface heating over the Qinghai-Xizang Plateau and ENSO cycle," Plateau Meteorol, vol. 26, pp. 39-46, 2007 (Chinese).

[10] H. Y. Zhao, X. H. Chen, X. W. Wan et al., "Climatic analysis and forecasting method of sand-dust storms in Northwest China," Journal of Desert Research, vol. 24, pp. 637-641, 2004 (Chinese).

[11] Y. L. Zhang, G. Z. Fan, D. W. Zhou et al., "The climate characteristics analysis of the wintertime Southern Branch Trough," Journal of Chengdu University of Information Technology, vol. 27, no. 2, pp. 196-201, 2012 (Chinese).

[12] T. Wang, S. Yang, Z. P. Wen, R. Wu, and P. Zhao, "Variations of the winter India-Burma Trough and their links to climate anomalies over southern and eastern Asia," Journal of Geophysical Research: Atmospheres, vol. 116, no. D23, pp. n/a-n/a, 2011.

[13] B. Lu and H.-L. Ren, "SST-forced interdecadal deepening of the winter India-Burma trough since the 1950s," Journal of Geophysical Research: Atmospheres, vol. 121, no. 6, pp. 2719-2731, 2016.

[14] J. Cao, P. Yao, L. Wang, and K. Liu, "Summer rainfall variability in low-latitude highlands of China and subtropical Indian 
Ocean dipole," Journal of Climate, vol. 27, no. 2, pp. 880-892, 2014.

[15] D. Barriopedro, C. M. Gouveia, R. M. Trigo, and L. Wang, "The 2009/10 drought in China: Possible causes and impacts on vegetation," Journal of Hydrometeorology, vol. 13, no. 4, pp. 12511267, 2012.

[16] J. Yang, D. Y. Gong, W. S. Wang, M. Hu, and R. Mao, "Extreme drought event of 2009/2010 over southwestern China," Meteorology and Atmospheric Physics, vol. 115, no. 3-4, pp. 173-184, 2012.

[17] W. J. Zhang, F. F. Jin, J. X. Zhao, L. Qi, and H. L. Ren, "The possible influence of a nonconventional El Niño on the severe autumn drought of 2009 in Southwest China," Journal of Climate, vol. 26, no. 21, pp. 8392-8405, 2013.

[18] L. Wang and W. Chen, "A CMIP5 multimodel projection of future temperature, precipitation, and climatological drought in China," International Journal of Climatology, vol. 34, no. 6, pp. 2059-2078, 2014.

[19] Y. Yin, D. Ma, S. Wu, and T. Pan, "Projections of aridity and its regional variability over China in the mid-21st century," International Journal of Climatology, vol. 35, no. 14, pp. 43874398, 2015.

[20] J. Q. Zhai, J. L. Huang, B. D. Su et al., "Intensity-area-duration analysis of droughts in China 1960-2013," Climate Dynamics, vol. 48, no. 1-2, pp. 151-168, 2017.

[21] C. Hao, J. Zhang, and F. Yao, "Multivariate drought frequency estimation using copula method in Southwest China," Theoretical and Applied Climatology, vol. 127, no. 3-4, pp. 977-991, 2017.

[22] J. M. Lü, J. H. Ju, J. Z. Ren, and W. W. Gan, “The influence of the Madden-Julian Oscillation activity anomalies on Yunnan's extreme drought of 2009-2010," Science China Earth Sciences, vol. 55, no. 1, pp. 98-112, 2012 (Chinese).

[23] X. M. Wang, S. W. Zhou, and B. Zhou, "Causative analysis of continuous drought in southwest China from Autumn 2009 to Spring 2010," Meteorological Monthly, vol. 38, no. 11, pp. 13991407, 2012.

[24] X. Z. Liu and W. Zhou, "Modulation of the interannual variation of the India-Burma Trough on the winter moisture supply over Southwest China," Climate Dynamics, vol. 46, no. 1-2, pp. 147$158,2016$.

[25] X. Li, Y. Q. D. Chen, and W. Zhou, "Response of winter moisture circulation to the India-Burma trough and its modulation by the South Asian waveguide," Journal of Climate, vol. 30, no. 4, pp. 1197-1210, 2017.

[26] F. Y. Wei, Modern climatic statistical diagnosis and prediction technology, China Meteorological Press, 2nd edition, 2007, pp. 63-70.

[27] C. Sun and S. Yang, "Persistent severe drought in southern China during winter-spring 2011: large-scale circulation patterns and possible impacting factors," Journal of Geophysical Research: Atmospheres, vol. 117, no. 10, pp. 63-74, 2012.

[28] NCC/CMA, "China Climate Impact Assessment. National climate center/China Meteorological Administration Rep 4 :19pp, 2012".

[29] H. Yang and S. Q. Sun, "The characteristics of longitudinal movement of the subtropical high in the western Pacific in the pre-rainy season in South China," Advances in Atmospheric Sciences, vol. 22, no. 3, pp. 392-400, 2005.

[30] K. E. Trenberth and J. W. Hurrell, "Decadal atmosphere-ocean variations in the Pacific," Climate Dynamics, vol. 9, no. 6, pp. 303-319, 1994.
[31] Intergovernmental Panel on Climate Change, Summary for Policymakers of the Synthesis Report of the IPCC Fourth Assessment Report, Cambridge University Press, UK, 2007. 

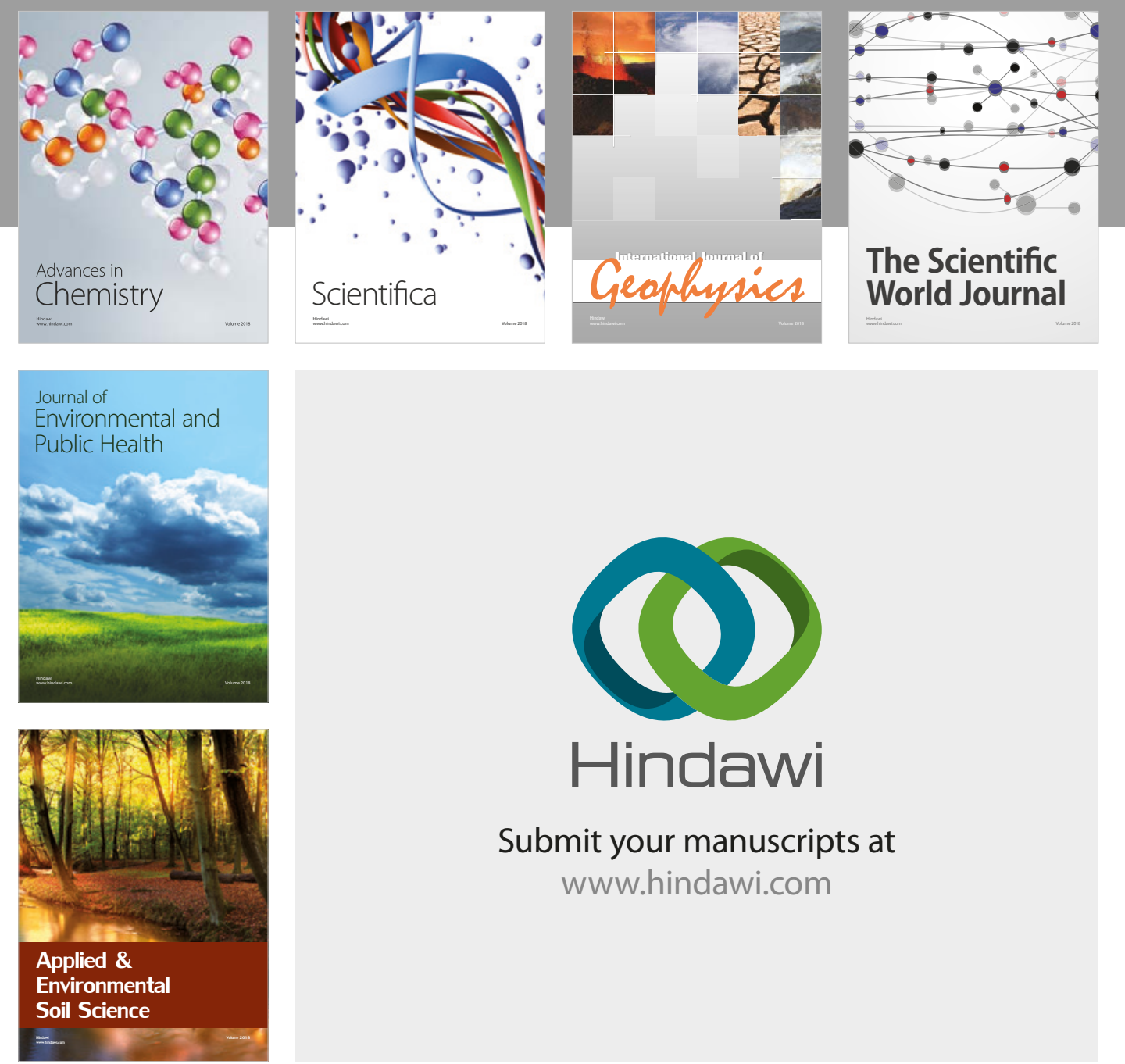

The Scientific

\section{World Journal}
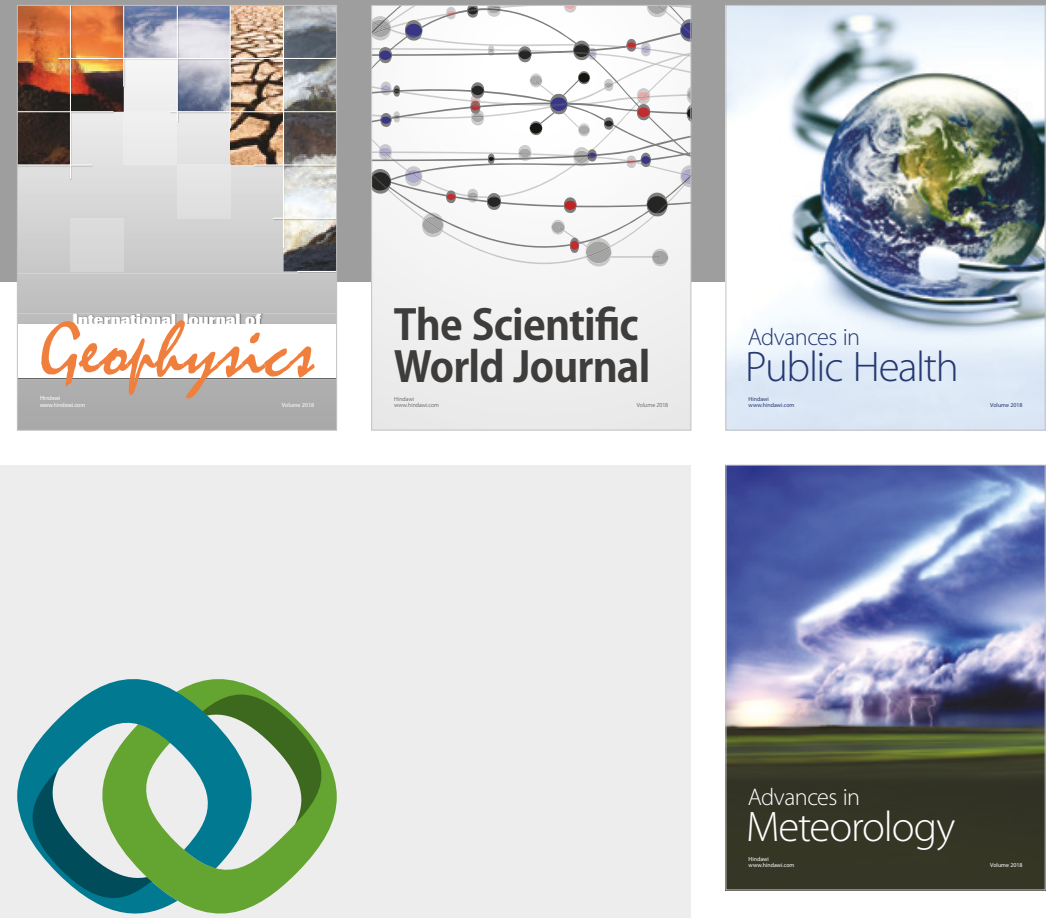

Advan

Public Health

\section{Hindawi}

Submit your manuscripts at

www.hindawi.com
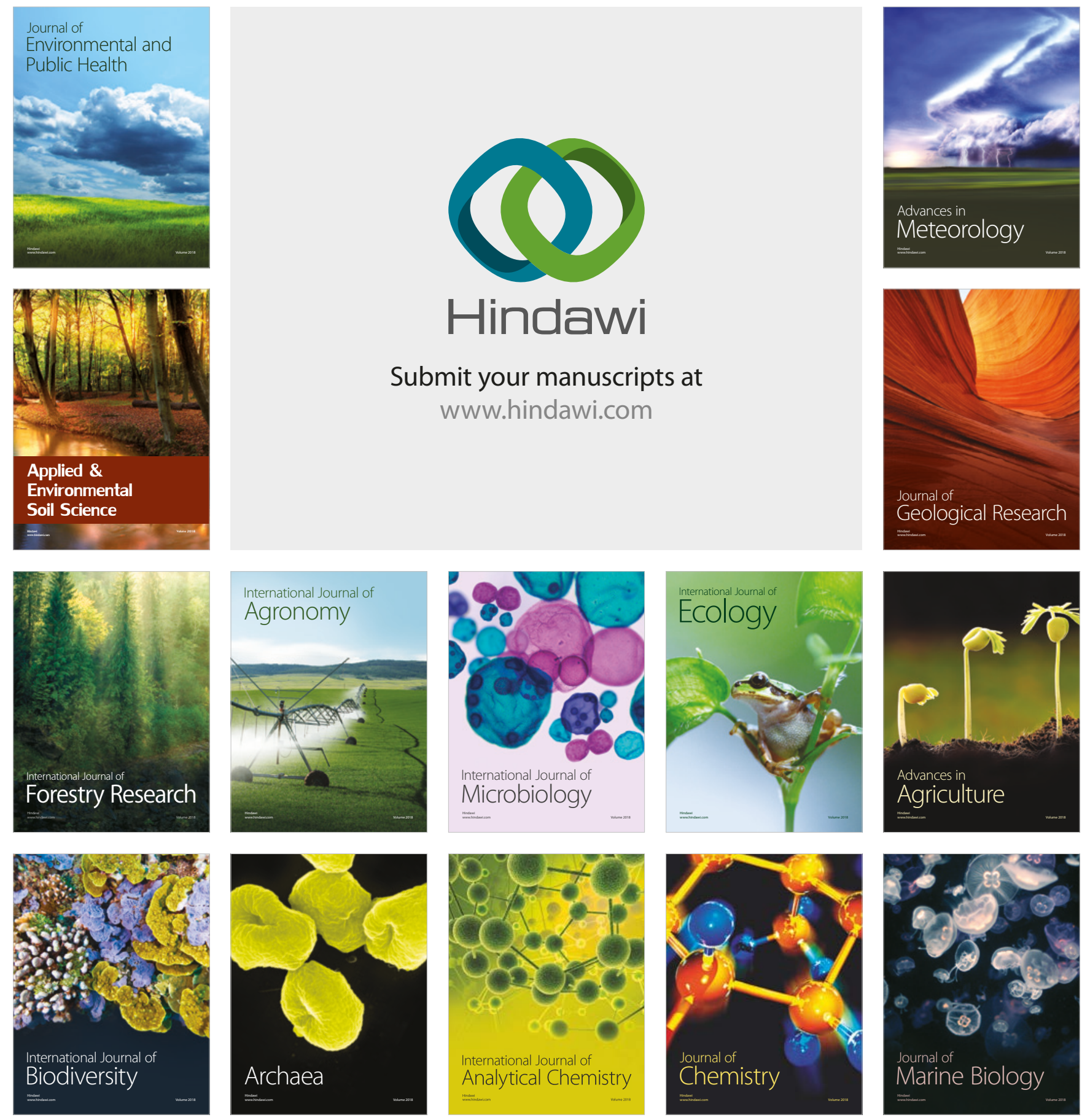